\title{
INFluência de HeRbicidas e de Sistemas de SemeaduRa de Brachiaria brizantha CoNSORCIADA COM MILHO ${ }^{1}$
}

\author{
Influence of Herbicides and Sowing Systems on Maize - Brachiaria brizantha Intercrop
}

JAKELAITIS, A. ${ }^{2}$, SILVA, A.F. ${ }^{3}$, SILVA, A.A. ${ }^{4}$, FERREIRA, L.R. ${ }^{4}$, FREITAS, F.C.L. ${ }^{2}$ e VIVIAN,.$^{2}$

\begin{abstract}
RESUMO - O objetivo deste trabalho foi avaliar a ocorrência de plantas daninhas, o estado nutricional e a produtividade do milho e de Brachiaria brizantha consorciados em diferentes arranjos de semeadura da braquiária, tratados com a mistura dos herbicidas nicosulfuron + atrazine e atrazine. Nas parcelas, os tratamentos foram constituídos das semeaduras de milho e $B$. brizantha em monocultivo, mais quatro formas de estabelecimento da braquiária, representadas pela semeadura de uma e duas linhas de braquiária na entrelinha do milho; pela semeadura na mesma linha do milho; e pela semeadura da forrageira a lanço na entrelinha do milho. Nas subparcelas, os dois tratamentos secundários constaram do uso da mistura dos herbicidas nicosulfuron + atrazine $\left(8+1.500 \mathrm{~g} \mathrm{ha}^{-1}\right)$ e atrazine $\left(1.500 \mathrm{~g} \mathrm{ha}^{-1}\right)$, aplicados aos 30 dias após a emergência (DAE) do milho. Foram avaliados a biomassa seca da comunidade infestante aos 30 dias após a aplicação (DAA) dos herbicidas, os níveis de macronutrientes, o rendimento de grãos e o peso de mil sementes no milho, bem como a produção de biomassa seca total e o acúmulo de macronutrientes pela forrageira. As espécies Brachiaria plantaginea, Brachiaria decumbens e Sorghum arundinaceum foram controladas pela mistura de nicosulfuron + atrazine; entretanto, as demais espécies, constituídas por Digitaria horizontalis, Cyperus rotundus e Artemisia verlotorum, não foram controladas pela mistura de herbicidas. Menores niveis de clorofila total e de $\mathrm{N}$ nas folhas de milho foram observados quando cultivadas duas linhas de braquiária na entrelinha do milho. Quando se utilizou a mistura de nicosulfuron + atrazine, foram observados no milho maiores teores de clorofila total, N, P e K e de rendimento de grãos e peso de mil sementes, comparados aos tratamentos que não receberam esses produtos. Ao utilizar duas linhas da semeadura de $B$. brizantha em associação com o milho, foi observada maior ocupação do solo pelas espécies cultivadas, maior produção de forragem e, conseqüentemente, maior quantidade de nutrientes incorporada a essa biomassa, sem afetar significativamente a produção da cultura.
\end{abstract}

Palavras-chave: integração agricultura-pecuária, nicosulfuron, atrazine.

\begin{abstract}
The aim of this study was to evaluate the occurrence of weeds, nutritional state and yield of maize - B. brizantha intercrop under different layouts of Brachiaria pasture sowing treated with the herbicide mixture nicosulfuron + atrazine and atrazine. In the plots, the treatments consisted in maize and $\boldsymbol{B}$. brizantha sowing in single crops, besides four forms of establishing $\boldsymbol{B}$. brizantha by sowing one and two rows of $\boldsymbol{B}$. brizantha in-between the maize rows; sowing along the same row as maize; and sowing the forage scattered in-between the maize rows. In the subplots, the two secondary treatments consisted in using the herbicide mixture nicosulfuron + atrazine $\left(8+1,500 \mathrm{~g} \mathrm{ha}^{-1}\right)$ and atrazine $\left(1,500 \mathrm{~g} \mathrm{ha}^{-1}\right)$ applied 30 days after emergence (DAE). Dry biomass of the macronutrient levels, grain yield and the weight of a thousand maize kernels, as well as the total dry matter yield and macronutrients accumulated by the pasture were evaluated. The weed species Brachiaria plantaginea, Brachiaria decumbens, and Sorghum arundinaceum were controlled by the mixture nicosulfuron + atrazine; the species Digitaria horizontalis, Cyperus rotundus, and Artemisia verlotorum were not controlled by the herbicide mixture. Lower levels of total chlorophyll and $N$ leaf contents in maize were
\end{abstract}

Recebido para publicação em 20.7.2004 e na forma revisada em 21.4.2005.

Pesquisa financiada pelo CNPq.

2 Doutorando do Departamento de Fitotecnia da Universidade Federal de Viçosa - UFV, 36570-000 Viçosa-MG; ${ }^{3}$ Estudante de Agronomia - UFV, Bolsista de Iniciação Científica do CNPq; ${ }^{4 /}$ Prof. do Departamento de Fitotecnia - UFV. 
observed when two rows of $\boldsymbol{B}$. brizantha were cultivated in-between the maize rows. When the herbicide mixture nicosulfuron + atrazine was used, highest levels of total chlorophyll, $N, P$, and $K$, grain yield, and weight of a thousand kernels were observed in maize compared to the treatments without product application. When two rows of $\boldsymbol{B}$. brizantha were cultivated in-between the maize rows, a greater occupation of soil by the cultivated species, greater yield forage and greater amount of nutrients incorporated of this biomass were observed, without significantly affecting maize yield grain.

Key words: crop-livestock integration, nicosulfuron, atrazine.

\section{INTRODUÇÃO}

O emprego de culturas anuais cultivadas em rotação, ou em consórcios com espécies forrageiras, tem constituído uma das principais estratégias de formação e reforma de pastagens no sistema integrado agricultura-pecuária. Nesse contexto, as culturas de interesse econômico têm sido exploradas, visando minimizar os custos de produção, principalmente em relação a adubação, preparo do solo e controle de plantas daninhas (Souza Neto, 1993). Em consórcio com forrageiras, especificamente Brachiaria spp., várias culturas têm sido empregadas, porém o milho tem sido a preferida, devido à sua tradição de cultivo, ao grande número de cultivares comerciais adaptados a diferentes regiões ecológicas do Brasil e à excelente adaptação, quando manejado em consórcio.

Trabalhos realizados por Kluthcouski et al. (1991) e Portes et al. (2000) têm demonstrado a viabilidade técnica de sistemas consorciados entre culturas e forrageiras. No consórcio de Brachiaria brizantha com milho, Portes et al. (2000) verificaram que a competição e o sombreamento exercidos pelo milho afetaram o crescimento, o perfilhamento e o rendimento forrageiro de $B$. brizantha até a colheita da cultura. Cobucci (2001) relata que, em vários ensaios sobre o consórcio de $B$. brizantha com o milho, a presença da forrageira não afetou esta cultura, e em outros ensaios foi necessário o uso do herbicida nicosulfuron em subdoses para reduzir o crescimento da forrageira e, com isso, garantir o bom rendimento da cultura. No entanto, a eficiência técnica desses sistemas depende de certas condições, que são particulares de cada ambiente (Sanches \& Salinas, 1981; Cruz Filho, 1988). A compatibilidade entre espécies, a fertilidade do solo, a ocorrência de plantas daninhas e a competição entre as espécies consorciadas pelos recursos do meio podem influenciar o estabelecimento da forrageira e a produção satisfatória da cultura.

Semelhantemente aos monocultivos, as espécies consorciadas estão sujeitas à competição promovida pelas espécies daninhas. Os efeitos negativos dessa interferência podem inviabilizar esse consórcio, por meio dos prejuizos que podem ocorrer no estabelecimento da forrageira associada, no rendimento de grãos e na qualidade do produto colhido. Desse modo, as práticas culturais - como a forma de implantação da cultura em consórcio com a forrageira, a época e a forma de estabelecimento da forrageira e o arranjo entre plantas - podem minimizar a competição entre as espécies consorciadas e a ocorrência de plantas daninhas. Diante disso, objetivou-se avaliar a ocorrência de plantas daninhas, o estado nutricional e a produtividade do milho e de Brachiaria brizantha consorciados em diferentes arranjos de semeadura da braquiária, tratados com a mistura dos herbicidas nicosulfuron + atrazine e atrazine.

\section{MATERIAL E MÉTODOS}

O experimento foi realizado em campo, em semeadura direta sobre Argissolo VermelhoAmarelo câmbico, em Coimbra, MG, no período de novembro de 2002 a abril de 2003. Quinze dias antes da semeadura, fez-se a dessecação química da área com glyphosate +2,4-D (1,44 $+0,335 \mathrm{~kg} \mathrm{ha}^{-1}$ ) e a coleta de solo à profundidade de $0,20 \mathrm{~m}$, cuja análise química constou de $\mathrm{pH}$ em água de 5,6; $\mathrm{H}+\mathrm{Al}, \mathrm{Ca}$ e $\mathrm{Mg}$ de $2,7,2,40$ e $0,34 \mathrm{cmolc} \mathrm{dm}^{-3}$, respectivamente; $\mathrm{P}$ de $27 \mathrm{mg} \mathrm{dm}^{-3}$; $\mathrm{K}$ de $36 \mathrm{mg} \mathrm{dm}^{-3}$; e matéria orgânica de 2,1 dag $\mathrm{kg}^{-1}$. 
O delineamento experimental foi o de blocos casualizados em parcelas subdivididas, com quatro repetições. Nas parcelas, foram testados os monocultivos do milho e de $B$. brizantha, mais quatro formas de estabelecimento da forrageira em consórcio com o milho, representadas pela semeadura de uma e duas linhas da forrageira na entrelinha do milho, semeadura na mesma linha do milho e semeadura da forrageira a lanço na entrelinha do milho. As parcelas experimentais continham seis fileiras de milho, totalizando uma área de $120 \mathrm{~m}^{2}$, com subparcelas de $60 \mathrm{~m}^{2}$.

O milho, AG122, foi semeado em 13/11/ 2002 no espaçamento de $1 \mathrm{~m}$ entre fileiras, sendo utilizadas sete sementes por metro linear, na profundidade de $4 \mathrm{~cm}$, e adubação de $400 \mathrm{~kg} \mathrm{ha}^{-1}$ de NPK (formulação 08-28-16). $B$. brizantha $\mathrm{cv}$. Vitória foi semeada na densidade de $3 \mathrm{~kg} \mathrm{ha}^{-1}$ de sementes puras viáveis, com $76 \%$ de valor cultural. Quando a semeadura da forrageira ocorreu em linha, a profundidade foi de aproximadamente $1,5 \mathrm{~cm}$. A semeadura destas espécies foi simultânea, utilizando uma semeadora-adubadora específica para o sistema de semeadura direta. $\mathrm{Na}$ semeadura a lanço, as sementes da forrageira foram distribuídas manualmente, logo após a semeadura do milho. Utilizou-se o espaçamento de 0,50 m entre linhas para o monocultivo e para a semeadura de duas linhas de $B$. brizantha na entrelinha do milho.

Os dois tratamentos secundários, alocados nas subparcelas, constaram da mistura de herbicidas nicosulfuron + atrazine $(8+$ $\left.1.500 \mathrm{~g} \mathrm{ha}^{-1}\right)$ e atrazine (1.500 $\left.\mathrm{g} \mathrm{ha}^{-1}\right)$, aplicados aos 30 dias após a emergência do milho com pulverizador costal, equipado com pontas TT 110.02, espaçadas de $1 \mathrm{~m}$, e aplicando-se o equivalente a $85 \mathrm{~L} \mathrm{ha}^{-1}$ de calda. A aplicação desses herbicidas foi feita de manhã ( 8 horas), com céu claro, solo úmido, velocidade do vento inferior a $5 \mathrm{~km} \mathrm{~h}^{-1}$, umidade relativa do ar e temperatura de $90 \%$ e $24{ }^{\circ} \mathrm{C}$, respectivamente.

A população de plantas daninhas existente no momento da aplicação dos herbicidas era composta principalmente por Brachiaria plantaginea, Sorghum arundinaceum, Digitaria horizontalis e Bidens pilosa. As dicotiledôneas apresentavam de quatro a seis folhas, e as gramineas, de dois a três perfilhos. Aos 30 dias após a aplicação (DAA) dos herbicidas, avaliou-se a eficiência dos tratamentos sobre a biomassa seca das espécies daninhas, coletadas em quatro amostras de $1 \mathrm{~m}^{2}$ em cada subparcela.

Aos 40 dias após a semeadura foi feita a adubação de cobertura, com $100 \mathrm{~kg} \mathrm{ha}^{-1}$ de $\mathrm{N}$, aplicados na forma de uréia. Os demais tratos culturais realizados atenderam as exigências do milho, conforme as recomendações técnicas citadas por Fancelli \& Dourado Neto (2000).

No florescimento do milho, avaliaram-se os teores de clorofila na folha, medidos com o clorofilômetro SPAD, modelo Minolta, e os teores dos macronutrientes $\mathrm{N}, \mathrm{P}, \mathrm{K}, \mathrm{Ca}, \mathrm{Mg}$ e S. As leituras efetuadas com o medidor de clorofila foram feitas na folha-índice, em 10 plantas por parcela, as quais foram colhidas, secas em estufa de ventilação forçada de ar a $70{ }^{\circ} \mathrm{C}$ e moídas. Em seguida, parte desse material moído foi submetida à digestão sulfúrica, determinando-se o teor de N (Jackson, 1958), e outra parte à digestão nítrico-perclórica, para obtenção dos teores de $\mathrm{K}$, por fotometria de chama; de $\mathrm{P}$, pelo método do ácido ascórbico modificado (Braga \& Deffelipo, 1974); de Ca e $\mathrm{Mg}$, por espectrofotometria de absorção atômica; e de S, por turbidimetria do sulfato (Blanchar et al., 1965).

$\mathrm{Na}$ colheita do milho, em área útil de $14 \mathrm{~m}^{2}$ na subparcela, foram determinados $\mathrm{o}$ estande, o rendimento e o peso de mil grãos de milho. Na mesma época, em $2 \mathrm{~m}^{2}$ de área útil foi avaliado o rendimento forrageiro de $B$. brizantha. Da biomassa forrageira foram obtidos o teor e o acúmulo de macronutrientes, conforme metodologia exposta anteriormente.

Os resultados da biomassa seca da comunidade infestante, do rendimento forrageiro e do acúmulo de nutrientes foram transformados em $\mathrm{x}^{0,5}$, para análise. Os resultados foram submetidos à análise de variância e à comparação de médias pelo teste de Tukey a $5 \%$ de probabilidade.

\section{RESULTADOS E DISCUSSÃO}

Observou-se que não houve interação entre os arranjos de semeadura de $B$. brizantha e o uso de herbicidas para a comunidade infestante avaliada aos 30 DAA dos herbicidas. 
Entre as espécies daninhas, foi observada maior ocorrência de $B$. plantaginea, $S$. arundinaceum, D. horizontalis e $B$. decumbens, sendo B. plantaginea a mais importante (Tabela 1). De acordo com Cruz Filho et al. (1986), um dos fatores que influenciam a infestação de plantas daninhas consiste na eficiência do método de semeadura da forrageira. Apesar de não haver diferenças estatísticas entre arranjos de semeadura, constatou-se maior tendência de supressão de plantas daninhas, principalmente $B$. plantaginea e $S$. arundinaceum, no arranjo de semeadura de duas linhas de $B$. brizantha na entrelinha do milho (Tabela 1). Esse método de semeadura mostrou-se mais efetivo no estabelecimento inicial das plantas de $B$. brizantha, o que proporcionou maior ocupação da área pela forrageira e pela cultura e, em conseqüência, favoreceu o aumento da capacidade de interceptação de luz pelo dossel das plantas cultivadas, reduzindo a quantidade desse recurso para as plantas daninhas.

Quando se utilizou o herbicida atrazine no manejo de plantas daninhas, independentemente do sistema de semeadura da forrageira, constatou-se eficiência no controle de espécies dicotiledôneas, principalmente Bidens pilosa, e ineficiência no controle de gramíneas. O uso da subdose de nicosulfuron em mistura com atrazine proporcionou redução significativa no acúmulo de biomassa seca da maioria das espécies daninhas encontradas, especialmente B. plantaginea, S.arundinaceum e $B$. decumbens, em comparação ao uso de atrazine aplicado isoladamente em todas as combinações de arranjos de plantas (Tabela 1). Resultados semelhantes quanto à eficiência dessa mistura na cultura do milho são relatados por Bastiani (1997). Já as espécies $D$. horizontalis, Artemisia verlotorum e Cyperus rotundus não foram influenciadas pelos tratamentos.

Plântulas do gênero Brachiaria são, em sua maioria, consideradas suscetiveis em aplicações realizadas em pós-emergência precoce de nicosulfuron nas doses comerciais recomendadas e seus sintomas em plantas sensiveis se manifestam por clorose foliar, necrose e redução do crescimento (Lorenzi, 2000; Shim et al., 2003). Em Brachiaria platyphylla, Gallaher et al. (1999) observaram que a maior atividade desse herbicida sobre a enzima acetolactato sintase deveu-se à rápida absorção e translocação para as regiões meristemáticas de tecidos em desenvolvimento, onde essa enzima é mais ativa. Dessa forma, na forrageira o herbicida proporcionou determinado nivel de injúria nas plantas tratadas, cuja magnitude foi dependente da tolerância dessa espécie à subdosagem testada e do seu estádio de desenvolvimento em relação às plantas daninhas.

Tabela 1 - Biomassa seca das plantas daninhas B. plantaginea (BRAPL), B. decumbens (BRADE), D. horizontalis (DIGHO), S. arundinaceum (SORAR), A. verlotorum (ARTEV) e C. rotundus (CYPRO) avaliadas aos 30 dias após a aplicação dos herbicidas, em função dos tratamentos utilizados no consórcio da forrageira com o milho. Coimbra-MG, 2003

\begin{tabular}{|c|c|c|c|c|c|c|c|c|}
\hline \multirow{2}{*}{ Arranjo de semeadura } & \multicolumn{8}{|c|}{ Biomassa $\left(\mathrm{g} \mathrm{m}^{-2}\right)$} \\
\hline & BRAPL & BRADE & DIGHO & SORAR & ARTVE & CYPRO & Outras espécies & Total \\
\hline Duas linhas na entrelinha do milho & $17,93 \mathrm{a}$ & $4,70 \mathrm{a}$ & $15,70 \mathrm{a}$ & $6,87 \mathrm{a}$ & $1,52 \mathrm{a}$ & $1,16 \mathrm{a}$ & $0,34 \mathrm{a}$ & $48,21 \mathrm{a}$ \\
\hline A lanço & $30,09 \mathrm{a}$ & $5,64 \mathrm{a}$ & $18,92 \mathrm{a}$ & $22,67 \mathrm{a}$ & $0,60 \mathrm{a}$ & $2,86 \mathrm{a}$ & $0,24 \mathrm{a}$ & $81,02 \mathrm{a}$ \\
\hline Na linha de semeadura do milho & $31,67 \mathrm{a}$ & $3,44 \mathrm{a}$ & $12,22 \mathrm{a}$ & $26,75 \mathrm{a}$ & $1,79 \mathrm{a}$ & $2,42 \mathrm{a}$ & $1,24 \mathrm{a}$ & $79,51 \mathrm{a}$ \\
\hline Uma linha na entrelinha do milho & $36,34 \mathrm{a}$ & $4,31 \mathrm{a}$ & $16,72 \mathrm{a}$ & $22,56 \mathrm{a}$ & $1,52 \mathrm{a}$ & $1,76 \mathrm{a}$ & $0,93 \mathrm{a}$ & $84,13 \mathrm{a}$ \\
\hline B. brizantha solteira & $27,35 \mathrm{a}$ & $1,56 \mathrm{a}$ & $8,41 \mathrm{a}$ & $16,62 \mathrm{a}$ & $1,08 \mathrm{a}$ & $1,45 \mathrm{a}$ & $0,76 \mathrm{a}$ & $57,22 \mathrm{a}$ \\
\hline Milho solteiro & $26,39 \mathrm{a}$ & $6,05 \mathrm{a}$ & $15,80 \mathrm{a}$ & $22,28 \mathrm{a}$ & $1,59 \mathrm{a}$ & $3,08 \mathrm{a}$ & $0,32 \mathrm{a}$ & $75,50 \mathrm{a}$ \\
\hline \multirow{2}{*}{ Herbicida } & \multicolumn{8}{|c|}{ Biomassa $\left(\mathrm{g} \mathrm{m}^{-2}\right)$} \\
\hline & BRAPL & BRADE & DIGHO & SORAR & ARTVE & CYPRO & Outras espécies & Total \\
\hline Atrazine & $45,82 \mathrm{a}$ & $6,05 \mathrm{a}$ & 14,13 a & $36,99 \mathrm{a}$ & $1,38 \mathrm{a}$ & $1,79 \mathrm{a}$ & $1,04 \mathrm{a}$ & $107,20 \mathrm{a}$ \\
\hline Atrazine + Nicosulfuron & $10,77 \mathrm{~b}$ & $2,51 \mathrm{~b}$ & $15,13 \mathrm{a}$ & $2,27 \mathrm{~b}$ & $1,31 \mathrm{a}$ & $2,45 \mathrm{a}$ & $0,23 \mathrm{~b}$ & $34,67 \mathrm{~b}$ \\
\hline $\mathrm{CV}(\%)$ & 15,72 & 21,42 & 16,07 & 22,16 & 21,05 & 11,36 & 25,63 & 9,63 \\
\hline
\end{tabular}

Médias seguidas pelas mesmas letras nas colunas são estatisticamente iguais pelo teste de Tukey a 5\% de probabilidade. 
O rendimento forrageiro de $B$. brizantha avaliado no momento da colheita do milho não foi afetado de forma significativa pela interação testada e pelo uso dos herbicidas, ocorrendo diferenças apenas entre os arranjos de semeadura da forrageira (Tabela 2). A biomassa de $B$. brizantha em monocultivo foi superior às produções dos demais sistemas de semeadura utilizados no consórcio com o milho. Foi observado no consórcio que o vigor das plântulas de milho foi maior em relação às plântulas de $B$. brizantha e que, por essa razão, o crescimento inicial do milho foi mais rápido, o que gerou uma competição entre elas desfavorável à forrageira. Como planta dominante nesse consórcio, o desenvolvimento vegetativo de $B$. brizantha foi retardado devido ao sombreamento e à competição exercida pelo milho (Tabela 2).

Portes et al. (2000), pesquisando o consórcio de $B$. brizantha cv. Marandu com milho, arroz, milheto e sorgo, verificaram que a forrageira sofreu forte competição das culturas durante seu ciclo de convivência com elas. De acordo com Dias Filho $(2000,2002)$, $B$. brizantha sombreada reduz sua capacidade fotossintética, porém mostra determinada tolerância em resposta ao sombreamento, apresentando no ambiente sombreado maior área foliar especifica e razão de área foliar, visando maximizar a captura de luz, e baixo ponto de compensação luminoso, promovendo um balanço positivo de carbono mesmo com limitação luminosa.
Em consórcio, a máxima produção forrageira de $B$. brizantha foi obtida quando se utilizou o arranjo de duas linhas na entrelinha do milho, sendo ela superior às produções dos sistemas de semeadura de uma linha na entrelinha do milho, semeadura na mesma linha do milho e semeadura da forrageira a lanço, as quais foram semelhantes entre si (Tabela 2). Comparando a mesma distribuição de plantas de $B$. brizantha no monocultivo e no consórcio de duas linhas na entrelinha do milho, constatou-se que a presença do milho inibiu o desenvolvimento forrageiro em aproximadamente $65 \%$ ao longo do período de convivência (Tabela 2). Entre os demais arranjos, a semeadura de uma linha de $B$. brizantha na entrelinha do milho proporcionou menor ocupação e cobertura vegetal do solo pela forrageira, acarretando menor rendimento forrageiro se comparado à semeadura de duas linhas desta na entrelinha do milho (Tabela 2). De forma semelhante entre os tratamentos consorciados, a semeadura da forrageira na mesma linha do milho resultou em menor produção de biomassa, em decorrência de ela ser mais profunda em relação à isolada, o que promoveu a emergência mais tardia da forrageira, tornando com isso a competição mais desfavorável a esta, pois o sombreamento e a competição com as plantas já estabelecidas foram se tornando maiores (Tabela 2). Em semeaduras mais profundas, as plantas emergem tardiamente, se desenvolvem lentamente e dificilmente alcançam o nivel de produção

Tabela 2 - Biomassa seca total (BST) e teores de N, P, K, Ca, Mg e S em B. brizantha, em função dos tratamentos utilizados no consórcio desta com a cultura do milho. Coimbra-MG, 2003

\begin{tabular}{|c|c|c|c|c|c|c|c|}
\hline \multirow{2}{*}{ Arranjo de semeadura } & \multirow{2}{*}{$\begin{array}{c}\text { BST } \\
\left(\mathrm{kg} \mathrm{ha}^{-1}\right)\end{array}$} & \multicolumn{6}{|c|}{ Macronutriente $\left({\left.\text { dag } \mathrm{kg}^{-1}\right)}^{-1}\right.$} \\
\hline & & $\mathrm{N}$ & $\mathrm{P}$ & $\mathrm{K}$ & $\mathrm{Ca}$ & $\mathrm{Mg}$ & $\mathrm{S}$ \\
\hline Duas linhas na entrelinha do milho & $2.664,22 \mathrm{~b}$ & $1,11 \mathrm{~b}$ & $0,66 \mathrm{a}$ & $1,49 \mathrm{~d}$ & $0,31 \mathrm{a}$ & $0,24 \mathrm{a}$ & $0,07 \mathrm{a}$ \\
\hline A lanço & $450,50 \mathrm{c}$ & $1,26 \mathrm{a}$ & $0,71 \mathrm{a}$ & $2,22 \mathrm{a}$ & $0,31 \mathrm{a}$ & $0,23 \mathrm{a}$ & $0,09 \mathrm{a}$ \\
\hline Na linha de semeadura do milho & $714,71 \mathrm{c}$ & $1,31 \mathrm{a}$ & $0,67 \mathrm{a}$ & $1,97 \mathrm{~b}$ & $0,29 \mathrm{a}$ & $0,22 \mathrm{a}$ & $0,08 \mathrm{a}$ \\
\hline Uma linha na entrelinha do milho & $1.154,48 \mathrm{c}$ & $1,09 \mathrm{~b}$ & $0,62 \mathrm{a}$ & $1,68 \mathrm{c}$ & $0,29 a$ & $0,23 \mathrm{a}$ & $0,07 \mathrm{a}$ \\
\hline B.brizantha solteira & $7.633,78 \mathrm{a}$ & $0,78 \mathrm{c}$ & $0,41 \mathrm{~b}$ & $1,29 \mathrm{e}$ & $0,30 \mathrm{a}$ & $0,25 \mathrm{a}$ & $0,06 \mathrm{a}$ \\
\hline \multirow{2}{*}{ Herbicida } & \multirow{2}{*}{$\begin{array}{c}\text { BST } \\
\left(\mathrm{kg} \mathrm{ha}^{-1}\right)\end{array}$} & \multicolumn{6}{|c|}{ Macronutriente $\left({\left.\text { dag } \mathrm{kg}^{-1}\right)}^{-1}\right.$} \\
\hline & & $\mathrm{N}$ & $\mathrm{P}$ & $\mathrm{K}$ & $\mathrm{Ca}$ & $\mathrm{Mg}$ & $\mathrm{S}$ \\
\hline Atrazine & $2.801,86 \mathrm{a}$ & $1,04 \mathrm{a}$ & $0,57 \mathrm{a}$ & $1,61 \mathrm{a}$ & $0,29 a$ & $0,23 \mathrm{a}$ & $0,07 \mathrm{a}$ \\
\hline Atrazine + Nicosulfuron & $2.245,21 \mathrm{a}$ & $1,17 \mathrm{~b}$ & $0,66 \mathrm{~b}$ & $1,84 \mathrm{~b}$ & $0,31 \mathrm{a}$ & $0,24 \mathrm{a}$ & $0,08 \mathrm{a}$ \\
\hline CV (\%) & 16,14 & 6,73 & 8,02 & 7,05 & 5,86 & 6,72 & 13,97 \\
\hline
\end{tabular}

Médias seguidas pelas mesmas letras nas colunas são estatisticamente iguais pelo teste de Tukey a $5 \%$ de probabilidade. 
forrageiro daquelas que emergem mais cedo (Abreu, 1993). Quando a forrageira foi semeada a lanço, verificou-se também menor rendimento de forragem, em conseqüência do efeito da falta de contato das sementes com o solo (Tabela 2). A incorporação destas beneficia a germinação e a sobrevivência das plântulas, devido à proteção das sementes, à eficiência no aproveitamento da umidade e à facilidade de fixação das plântulas ao solo (Cruz Filho, 1988; Abreu, 1993).

Os teores de N, P e K na biomassa da parte aérea de $B$. brizantha apresentaram variação significativa em função dos tratamentos herbicidas e dos arranjos de semeadura. O teor de $\mathrm{N}$ na biomassa do monocultivo foi significativamente mais baixo comparado ao teor desse elemento na forragem proveniente do consórcio; entre as diferentes combinações de semeadura, a forrageira desenvolvida na mesma linha de semeadura do milho e a lanço apresentaram os maiores teores (Tabela 2). Os resultados concordam com as observações de Carvalho et al. (2002), de que o maior teor de $\mathrm{N}$ na biomassa de plantas cultivadas sob sombreamento possa ser atribuído a um efeito de concentração nas folhas, em virtude do menor rendimento forrageiro produzido nessa condição. Da mesma forma, Gloser (1993) comenta que plantas sombreadas e não-sombreadas nos primeiros estádios de crescimento vegetativo possuem aproximadamente a mesma concentração de $\mathrm{N}$ em seus tecidos. Entretanto, com o desenvolvimento vegetativo, o teor de $\mathrm{N}$ decresce rapidamente em plantas não-sombreadas, e o sombreamento, ao atrasar o desenvolvimento das plantas, permite manter elevado o teor de $\mathrm{N}$ na biomassa por mais tempo. Independentemente da condição de cultivo de $B$. brizantha, os teores de $\mathrm{N}$ encontrados situaram-se abaixo dos estabelecidos por Malavolta et al. (1986) como adequados para espécies do gênero Brachiaria.

Comportamento análogo ao do $\mathrm{N}$ foi observado para o $\mathrm{P}$, que apresentou teor mais baixo no monocultivo em relação aos tratamentos consorciados (Tabela 2). Em trabalhos realizados por Carvalho et al. (1995) e Castro et al. (2001) com diversas forrageiras tropicais se desenvolvendo em ambiente sombreado, os autores constataram que $B$. brizantha apresentou maior teor de P na biomassa forrageira e que o teor mais elevado desse elemento provavelmente se deve à menor produção de biomassa pelas plantas sombreadas. No entanto, plantas crescendo sob radiação solar direta sem atraso no seu desenvolvimento vegetativo tendem a reduzir os niveis de $\mathrm{P}$ na biomassa, em decorrência da redistribuição desse elemento dentro da planta (Minson, 1990). Os teores encontrados desse elemento na forragem ficaram acima da faixa critica, conforme Malavolta et al. (1986). Para o K, verificou-se relação linear entre o rendimento forrageiro das plantas nos diferentes arranjos de semeadura e o seu teor na biomassa (Tabela 2). Esse comportamento corrobora as observações de Carvalho et al. (1995), de que os maiores teores de $\mathrm{K}$ nas folhas de $B$. brizantha sombreada também se devem a seu menor rendimento forrageiro.

Entre os herbicidas, quando se utilizou atrazine em mistura com nicosulfuron, foram obtidos maiores teores de N, P e K na biomassa de $B$. brizantha, em relação aos tratamentos que receberam somente atrazine (Tabela 2). Esse comportamento pode ser atribuido ao controle nulo do atrazine sobre as gramineas infestantes que conviveram com a forrageira, o qual pode ter influenciado diretamente a utilização desses nutrientes pelas plantas. Entretanto, os teores de $\mathrm{Ca}, \mathrm{Mg}$ e $\mathrm{S}$ não foram influenciados pelos tratamentos.

Resultados publicados por Magalhães (1997) demonstram que $B$. brizantha possui boa capacidade de ciclagem de nutrientes, acumulando em sua biomassa aproximadamente $109 \mathrm{~kg} \mathrm{ha}^{-1}$ de $\mathrm{K}, 62 \mathrm{~kg} \mathrm{ha}^{-1}$ de $\mathrm{N} \mathrm{e}$ $12 \mathrm{~kg} \mathrm{ha}^{-1}$ de $\mathrm{P}$, Ca e $\mathrm{Mg}$ para seis toneladas de matéria seca disponível produzida em solos de cerrado. Considerando os teores médios obtidos na biomassa forrageira de todos os tratamentos, verificou-se que os nutrientes extraídos em maior quantidade e em ordem decrescente desde a semeadura até a colheita do milho foram potássio, nitrogênio, fósforo, cálcio, magnésio e enxofre (Tabela 3). O acúmulo desses nutrientes não foi influenciado pelo uso de herbicidas, mas apenas pelos diferentes arranjos de semeadura da forrageira; em monocultivo, mais nutrientes foram extraídos em relação aos tratamentos consorciados (Tabela 3). Em consórcio, os resultados 
relativos ao acúmulo de nutrientes na forragem evidenciaram a superioridade do arranjo de duas linhas de $B$. brizantha na entrelinha do milho, em comparação com os demais sistemas de semeadura (Tabela 3).

Os resultados obtidos com as características relacionadas à cultura do milho estão indicados na Tabela 4. Observou-se que o indice SPAD e o teor de $\mathrm{N}$ foram influenciados pelos diferentes arranjos de semeadura da forrageira com o milho e que essas características e os teores de $\mathrm{P}$ e $\mathrm{K}$, bem como o rendimento de grãos e o peso destes, foram significativamente afetados pelo manejo com herbicidas. Foi observado, no arranjo de duas linhas da forrageira na entrelinha do milho onde se obteve o maior rendimento forrageiro -, que o teor de clorofila total e o teor de $\mathrm{N}$ nas folhas de milho foram inferiores aos obtidos nos demais arranjos e no monocultivo do milho (Tabela 4). Segundo Argenta et al. (2002) e Rocha (2003), existe correlação positiva e significativa entre os valores obtidos com o medidor de clorofila e o teor de $\mathrm{N}$ nas folhas do milho, avaliados no florescimento com o rendimento de grãos.

Comparados aos valores de $\mathrm{N}$ estabelecidos por Malavolta et al. (1989) como adequados para a cultura $\left(2,75\right.$ a $3,25 \mathrm{dag} \mathrm{kg}^{-1}$ de $\mathrm{N}$ ), os teores encontrados nos tratamentos em que se utilizou atrazine e no arranjo de semeadura de duas linhas na entrelinha do milho se situaram abaixo da faixa considerada adequada. Entre os demais nutrientes, independentemente dos tratamentos, os teores de $\mathrm{P}, \mathrm{K}, \mathrm{Ca}$ e $\mathrm{Mg}$ se encontraram na faixa adequada e $\mathrm{S}$ ficou abaixo. O melhor estado nutricional da cultura, o maior rendimento de grãos e o peso de mil sementes foram alcançados com a utilização da mistura de nicosulfuron com atrazine. Nesse manejo se obteve redução na biomassa das principais espécies daninhas encontradas, especialmente $B$. plantaginea; ao mesmo tempo, a injúria promovida pelo nicosulfuron em $B$. brizantha contribuiu para minimizar a competição existente durante o período crítico de prevenção de interferência do milho (Tabela 4). B. plantaginea constitui importante planta daninha da cultura do milho da região CentroSul do Brasil, e a sua presença no início do periodo crítico de competição do milho pode resultar em perdas significativas no rendimento de grãos da cultura, caso seu manejo seja realizado de forma inadequada (Vidal et al., 2004). Conseqüentemente, em consórcio, a presença de altas infestações dessa espécie pode comprometer a integridade desse sistema.

De acordo com Sanches \& Salinas (1981), a associação entre espécies cultivadas é específica e depende das condições edafoclimáticas de cada local, devendo ser comprovada em cada agrossistema. Em ensaios realizados no Estado de Goiás, envolvendo o consórcio entre milho e $B$. brizantha, Cobucci (2001) não constatou interferência negativa da forrageira manejada com nicosulfuron nas doses de 0,8 ,

Tabela 3 - Acúmulo de N, P, K, Ca, Mg e S em B. brizantha, em função dos tratamentos utilizados no consórcio desta com a cultura do milho. Coimbra-MG, 2003

\begin{tabular}{|c|c|c|c|c|c|c|}
\hline \multirow{2}{*}{ Arranjo de semeadura } & \multicolumn{6}{|c|}{ Macronutriente $\left(\mathrm{kg} \mathrm{ha}^{-1}\right)$} \\
\hline & $\mathrm{N}$ & $\mathrm{P}$ & $\mathrm{K}$ & $\mathrm{Ca}$ & $\mathrm{Mg}$ & $\mathrm{S}$ \\
\hline Duas linhas na entrelinha do milho & $28,93 \mathrm{~b}$ & $17,23 \mathrm{~b}$ & $39,26 \mathrm{~b}$ & $8,21 \mathrm{~b}$ & $6,45 \mathrm{~b}$ & $1,91 \mathrm{~b}$ \\
\hline A lanço & $5,62 \mathrm{c}$ & $3,22 \mathrm{c}$ & $9,79 \mathrm{c}$ & $1,41 \mathrm{c}$ & $1,01 \mathrm{c}$ & $0,41 \mathrm{c}$ \\
\hline $\mathrm{Na}$ linha de semeadura do milho & $9,34 \mathrm{c}$ & $4,81 \mathrm{c}$ & $14,33 \mathrm{c}$ & $2,08 \mathrm{c}$ & $1,54 \mathrm{c}$ & $0,57 \mathrm{c}$ \\
\hline Uma linha na entrelinha do milho & $12,14 \mathrm{c}$ & $7,12 \mathrm{c}$ & $19,12 \mathrm{c}$ & $3,40 \mathrm{bc}$ & $2,61 \mathrm{c}$ & $0,81 \mathrm{bc}$ \\
\hline B.brizantha solteira & $59,31 \mathrm{a}$ & $30,44 \mathrm{a}$ & $97,29 \mathrm{a}$ & $22,58 \mathrm{a}$ & $19,25 \mathrm{a}$ & $4,93 \mathrm{a}$ \\
\hline \multirow{2}{*}{ Herbicida } & \multicolumn{6}{|c|}{ Macronutriente $\left(\mathrm{kg} \mathrm{ha}^{-1}\right)$} \\
\hline & $\mathrm{N}$ & $\mathrm{P}$ & $\mathrm{K}$ & $\mathrm{Ca}$ & $\mathrm{Mg}$ & $\mathrm{S}$ \\
\hline Atrazine & 23,49 a & $12,70 \mathrm{a}$ & $35,00 \mathrm{a}$ & $7,94 \mathrm{a}$ & $6,75 \mathrm{a}$ & $1,97 \mathrm{a}$ \\
\hline Atrazine + Nicosulfuron & $22,65 \mathrm{a}$ & $12,43 \mathrm{a}$ & $36,92 \mathrm{a}$ & $7,13 \mathrm{a}$ & $5,59 \mathrm{a}$ & $1,49 \mathrm{a}$ \\
\hline CV (\%) & 15,34 & 16,98 & 15,73 & 16,67 & 16,41 & 18,34 \\
\hline
\end{tabular}

Médias seguidas pelas mesmas letras nas colunas são estatisticamente iguais pelo teste de Tukey a 5\% de probabilidade. 
Tabela 4 - Teor de clorofila total (CL) e teores de N, P, K, Ca, Mg e S, produção de grãos (PG) e peso de mil sementes (PS), em função dos tratamentos utilizados no consórcio do milho com Brachiaria brizantha. Coimbra-MG, 2003

\begin{tabular}{|c|c|c|c|c|c|c|c|c|c|}
\hline \multirow{2}{*}{ Arranjo de semeadura } & \multirow{2}{*}{$\mathrm{CL}$} & \multicolumn{6}{|c|}{ Macronutrientes $\left(\right.$ dag kg $\left.^{-1}\right)$} & \multirow{2}{*}{$\begin{array}{c}\mathrm{PG} \\
\left(\mathrm{tha}^{-1}\right)\end{array}$} & \multirow{2}{*}{$\begin{array}{l}\text { PS } \\
\text { (g) }\end{array}$} \\
\hline & & $\mathrm{N}$ & $\mathrm{P}$ & $\mathrm{K}$ & $\mathrm{Ca}$ & $\mathrm{Mg}$ & $\mathrm{S}$ & & \\
\hline Duas linhas na entrelinha do milho & $52,74 \mathrm{~b}$ & $2,49 \mathrm{~b}$ & $0,34 \mathrm{a}$ & $1,90 \mathrm{a}$ & $0,35 \mathrm{a}$ & $0,32 \mathrm{a}$ & $0,11 \mathrm{a}$ & 5,03 a & $267,92 \mathrm{a}$ \\
\hline A lanço & $55,40 \mathrm{a}$ & $2,84 \mathrm{a}$ & $0,37 \mathrm{a}$ & $2,18 \mathrm{a}$ & $0,37 \mathrm{a}$ & $0,31 \mathrm{a}$ & $0,11 \mathrm{a}$ & $5,77 \mathrm{a}$ & $285,97 \mathrm{a}$ \\
\hline Na linha de semeadura do milho & $56,84 \mathrm{a}$ & $2,82 \mathrm{a}$ & $0,37 \mathrm{a}$ & $2,12 \mathrm{a}$ & $0,35 \mathrm{a}$ & $0,36 \mathrm{a}$ & $0,13 \mathrm{a}$ & $5,55 \mathrm{a}$ & $292,66 \mathrm{a}$ \\
\hline Uma linha na entrelinha do milho & $55,45 \mathrm{a}$ & $2,90 \mathrm{a}$ & $0,38 \mathrm{a}$ & $2,05 \mathrm{a}$ & $0,36 \mathrm{a}$ & $0,35 \mathrm{a}$ & $0,13 \mathrm{a}$ & $5,57 \mathrm{a}$ & $279,84 \mathrm{a}$ \\
\hline Milho solteiro & $55,88 \mathrm{a}$ & $2,83 \mathrm{a}$ & $0,40 \mathrm{a}$ & $2,23 \mathrm{a}$ & $0,39 \mathrm{a}$ & $0,35 \mathrm{a}$ & $0,13 \mathrm{a}$ & $5,91 \mathrm{a}$ & $286,88 \mathrm{a}$ \\
\hline \multirow{2}{*}{ Herbicida } & \multirow{2}{*}{$\mathrm{CL}$} & \multicolumn{6}{|c|}{ Macronutrientes $\left(\mathrm{dag} \mathrm{kg}^{-1}\right)$} & PG & PS \\
\hline & & $\mathrm{N}$ & $\mathrm{P}$ & $\mathrm{K}$ & $\mathrm{Ca}$ & $\mathrm{Mg}$ & $\mathrm{S}$ & $\left(\mathrm{t} \mathrm{ha}^{-1}\right)$ & (g) \\
\hline Atrazine & $54,51 \mathrm{~b}$ & $2,65 b$ & $0,36 \mathrm{~b}$ & $1,97 \mathrm{~b}$ & $0,36 \mathrm{a}$ & $0,33 \mathrm{a}$ & $0,12 \mathrm{a}$ & $5,27 \mathrm{~b}$ & $271,57 \mathrm{~b}$ \\
\hline Atrazine + Nicosulfuron & $56,02 \mathrm{a}$ & $2,90 \mathrm{a}$ & $0,39 \mathrm{a}$ & $2,22 \mathrm{a}$ & $0,37 \mathrm{a}$ & $0,34 \mathrm{a}$ & $0,12 \mathrm{a}$ & $5,86 \mathrm{a}$ & $293,73 \mathrm{a}$ \\
\hline $\mathrm{CV} \%$ & 4,02 & 8,76 & 7,28 & 14,01 & 8,44 & 16,70 & 17,80 & 9,20 & 6,26 \\
\hline
\end{tabular}

Médias seguidas pelas mesmas letras nas colunas são estatisticamente iguais pelo teste de Tukey a 5\% de probabilidade.

12 e $20 \mathrm{~g} \mathrm{ha}^{-1}$ em mistura com $1.000 \mathrm{~g} \mathrm{ha}^{-1} \mathrm{de}$ atrazine sobre o rendimento de grãos da cultura. Ao contrário, em trabalhos realizados em Minas Gerais, Cruz Filho (1988) constatou diferenças na produção de milho consorciado com forrageiras e que os resultados variaram em função da espécie forrageira associada à cultura, das condições locais e do método de semeadura da forrageira.

Nesta pesquisa foi observado que, independentemente de como a forrageira foi estabelecida junto à cultura, o uso do herbicida nicosulfuron em mistura com atrazine foi necessário para atingir o controle satisfatório sobre a maioria das plantas daninhas presentes nesse agrossistema e permitir com esse manejo o rendimento de grãos de milho compatível com a produção de forragem. Por outro lado, ao utilizar duas linhas da semeadura de $B$. brizantha em associação com o milho, foi obtida maior ocupação do solo pelas espécies cultivadas, maior produção de forragem e, conseqüentemente, maior quantidade de nutrientes incorporada a essa biomassa, sem afetar significativamente a produção da cultura.

\section{LITERATURA CITADA}

ABREU, J. G. Influência da profundidade de semeadura e da pressão de compactação no solo sobre a emergência de Brachiaria brizantha Stapf cv. Marandu. 1993. $65 \mathrm{f}$. Dissertação (Mestrado em Solos e Nutrição de Plantas) Universidade Federal de Viçosa, Viçosa, 1993.
ARGENTA, G. et al. Parâmetros da planta como indicadores do nível de nitrogênio na cultura do milho. Pesq. Agropec. Bras., v. 37, n. 4. p. 519-527, 2002.

BASTIANI, M. L. R. Atividade dos herbicidas nicosulfuron e atrazine, em condições de casa de vegetação e de campo. 1997. 59 f. Dissertação (Mestrado em Fitotecnia) - Universidade Federal de Viçosa, Viçosa, 1997.

BLANCHAR, R. W.; REM, G.; CALDWELL, A. C. Sulfur in plant material by digestion with nitric and perchloric acid. Proc. Soil Sci. Soc. Am., v. 29, p. 71-72, 1965.

BRAGA, J. M.; DEFFELIPO, B. V. Determinação espectrofotométrica de fósforo em extratos de solo e plantas. Ceres, v. 21, p. 73-85, 1974.

CARVAlHO, M. M. et al. Crescimento inicial de cinco gramíneas tropicais em um sub-bosque de angico-vermelho (Anadenanthera macrocarpa Benth). Past. Trop., v. 17., n. 1, p. 24-30, 1995.

CARVALHO, M. M. et al. Início do florescimento, produção e valor nutritivo de gramíneas forrageiras tropicais sob condição de sombreamento natural. Pesq. Agropec. Bras., v. 37, n. 5, p. 717-722, 2002.

CASTRO, C. R. T. et al. Efeitos do sombreamento na composição mineral de gramíneas forrageiras tropicais. R. Bras. Zootec., v. 30, p. 1959-1968, 2001. (Suplemento, 6)

COBUCCI, T. Manejo integrado de plantas daninhas em sistema de plantio direto. In: ZAMBOLIM, L. (Ed.) Manejo integrado fitossanidade: cultivo protegido, pivô central e plantio direto. Viçosa: UFV, 2001. p.583-624.

CRUZ FILHO, A. B. et al. Comparação entre métodos de Brachiaria decumbens em pastagens de capim-gordura em áreas montanhosas. R. Bras. Zootec., v. 15, n. 4, p. 297-306, 1986. 
CRUZ FILHO, A. B. Práticas agronômicas para o estabelecimento de pastagens. In: MANEJO de pastagens. Pindamonhangaba: DIRA, 1988. p. 10-25.

DIAS FILHO, M. B. Growth and biomass allocation of the $\mathrm{C}_{4}$ grasses Brachiaria brizantha and $B$. humidicola under shade. Pesq. Agropec. Bras., v. 35:12, p. 2335-2341, 2000.

DIAS FILHO, M. B. Photosynthetic light response of the $\mathrm{C}_{4}$ grasses Brachiaria brizantha and Brachiaria humidicola under shade. Sci.Agric., v. 59, n. 1, p. 65-68, 2002.

FANCELLI, A. L.; DOURADO-NETO, D. Produção de milho. Guaíba: 2000. 360 p.

GALLAHER, K. et al. Absortion, translocation and metabolism of primisulfuron and nicosulfuron in broadleaf signalgrass (Brachiaria platyphylla) and corn. Weed Sci., v. 47, p. $8-12,1999$.

GLOSER, J. Growth rate and total nonstructural sacharides content in Alopecurus pratensis L. Biol. Plant., v. 35, n. 1, p. 37-42, 1993.

JACKSON, M. L. Nitrogen determination for soil and plant tissue. In: JACKSON, M. L. (Ed.). Soil chemical analysis. New Jersey, 1958. p. 183-204.

KLUTHCOUSKI, J. et al. Renovação de pastagens de cerrado com arroz. I. Sistema Barreirão, Goiânia: EMBRAPA-CNAPF, 1991. 20 p. (Documentos, 33).

LORENZI, H. Manual de identificação e controle de plantas daninhas. 5.ed. Nova Odessa: Instituto Plantarum, 2000. 384 p.

MAGALHÃES, R. T. Evolução das propriedades físicas e químicas de solos submetidos ao manejo pelo Sistema Barreirão. 1997. 86 f. Dissertação (Mestrado em Fitotecnia) - Universidade Federal de Goiás, Goiânia, 1997.
MALAVOLTA, E. et al. Avaliação do estado nutricional das plantas: princípios e aplicações. Piracicaba: POTAFOS, 1989. $201 \mathrm{p}$.

MALAVOLTA, E. et al. Exigências nutricionais das plantas forrageiras. In: MATTOS, H. B. (Ed.) Calagem e adubação de pastagens. Piracicaba: Associação Brasileira para Pesquisa da Potassa e do Fosfato, 1986. p. 31-91.

MINSON, D. J. Forage in ruminant nutrition. San Diego: Academic Press, 1990. 483 p.

PORTES, T. A. et al. Análise do crescimento de uma cultivar de braquiária em cultivo solteiro e consorciado com cereais. Pesq. Agropec. Bras., v. 35, n. 7, p. 1349-1358, 2000.

ROCHA, R. C. N. Respostas de híbridos de milho e ciclo superprecoce, precoce e normal à aplicação de nitrogênio no sistema de plantio direto. 2003. $47 \mathrm{f}$. Dissertação (Mestrado em Fitotecnia) - Universidade Federal de Viçosa, Viçosa, 2003.

SANCHES, P. A.; SALINAS, J. G. Low input technology for managing Oxisols in Tropical América. Adv. Agron., v. 34, p. 279-406, 1981.

SHIM, S.I. et al. Response of leaf acetolactate synthase from different leaf positions and seedling ages to sulfonylureia herbicide. Pest. Bioch. Physiol., v. 75, p. 39-46, 2003.

SOUZA NETO, J. M. Formação de pastagens de Brachiaria brizantha cv. Marandu com o milho como cultura acompanhante. 1993. 58 f. Dissertação (Mestrado em Fitotecnia) - Escola Superior de Agricultura "Luiz de Queiroz", Piracicaba, 1993.

VIDAL, R. A. et al. Nível de dano econômico de Brachiaria plantaginea na cultura de milho irrigado. Planta Daninha, v. 22, n. 1, p. 63-69, 2004. 